\title{
Cognitive behavioural therapy delivered by nurses improved insight and overall symptomatology in schizophrenia
}

Turkington D, Kingdon D, Turner T.Effectiveness of a brief cognitive-behavioural therapy intervention in the treatment of schizophrenia. Br J Psychiatry 2002;180:523-7.

\section{QUESTION: In patients with schizophrenia in secondary care settings, does cognitive behavioural therapy (CBT) delivered by community psychiatric nurses (CPNs) improve symptoms?}

\section{Design}

Randomised \{allocation concealed*\}†, unblinded,* controlled trial with 2-3 months of follow up.

\section{Setting}

6 centres in the UK (Belfast, Glasgow, Hackney, Newcastle, Southampton, and Swansea).

\section{Patients}

422 patients who were 18-65 years of age (mean age 40 y, $77 \%$ men) and were receiving treatment from psychiatric secondary care services. Exclusion criteria were need for inpatient care or intensive home treatment, primary diagnosis of drug or alcohol dependence, organic brain disease, or learning disability that could affect rating. Follow up was $84 \%$.

\section{Intervention}

Patients were allocated to CBT given by a CPN $(n=257)$ or treatment as usual $(\mathrm{n}=165)$. CPNs received 10 days of intensive training in CBT and were tested through demonstration, role play, and written examination. Patients saw the CPN for up to 6 one hour sessions over 2-3 months. All phases of CBT were included: assessment and engaging, developing explanations, case formulation, symptom management, adherence, working with core beliefs, and relapse prevention. Treatment as usual consisted of care by community mental health teams.

\section{Main outcome measures}

Overall symptomatology (Comprehensive Psychopathological Rating Scale), insight (Insight Rating Scale), and carer burden (Burden of Care Questionnaire). Secondary outcomes were change in schizophrenic symptoms (Schizophrenia Change Score) and depression (Montgomery-Åsberg Rating Scale).

\section{Main results}

Analysis was by intention to treat. The CBT group had a greater improvement in overall symptomatology and insight and a greater reduction in depression than the treatment as usual group; the groups did not differ for burden of care or change in schizophrenic symptoms (table).

\section{Conclusion}

In patients with schizophrenia in secondary care settings, cognitive behavioural therapy delivered by community psychiatric nurses improved insight and overall symptomatology and reduced depression.
*See glossary.

$\dagger$ Information provided by author.

Source of funding: Pfizer Ltd.

For correspondence: Dr D Turkington, University of Newcastle-upon-Tyne Newcastle-upon-Tyne, UK.

douglas.turkington@ ncl.ac.uk

Cognitive behavioural therapy by nurses v treatment as usual for schizophrenia

\begin{tabular}{|c|c|c|c|c|}
\hline \multirow{2}{*}{$\begin{array}{l}\text { Outcomes at } 2-3 \\
\text { months }\end{array}$} & \multicolumn{2}{|c|}{$\begin{array}{l}\text { Mean change from baseline score } \\
(95 \% \mathrm{CI})\end{array}$} & \multirow{2}{*}{$\begin{array}{l}\text { Difference in } \\
\text { mean change } \\
\text { score }\end{array}$} & \multirow[b]{2}{*}{ NNT } \\
\hline & CBT & Treatment as usual & & \\
\hline $\begin{array}{l}\text { Overall symptoms } \\
\text { (CPRS) }\end{array}$ & 3.65 (2.4 to 4.9 ) & $1.69(-0.004$ to 3.3$)$ & $-2.3(p=0.015) \S$ & 13 \\
\hline Insight (IRS) & $-1.2(-1.6$ to 0.8$)$ & $0.1(-0.4$ to 0.6$)$ & $1.3(p<0.001) \S$ & 10 \\
\hline $\begin{array}{l}\text { Depression } \\
\text { (AMRS) }\end{array}$ & $0.8(0.4$ to 1.3$)$ & $0.3(-0.3$ to 0.9$)$ & $-0.9(p=0.003) \S$ & 9 \\
\hline $\begin{array}{l}\text { Schizophrenic } \\
\text { symptoms (SCS) }\end{array}$ & $0.6(0.1$ to 1.0$)$ & $0.3(-0.2$ to 0.9$)$ & $-0.4(p=0.258)$ & NS \\
\hline $\begin{array}{l}\text { Burden of care } \\
\text { (BCQ) }\end{array}$ & $-2.2(-0.7$ to 5.0$)$ & $-1.0(-6.8$ to 4.8$)$ & $-4.3(p=0.126)$ & NS \\
\hline
\end{tabular}

†AMRS = Åsberg-Montgomery Rating Scale; BCQ = Burden of Care Questionnaire; CPRS = Comprehensive Psychopathological Rating Scale; IRS = Insight Rating Scale; NNT = number needed to treat for 1 additional person to have a $>50 \%$ improvement; NS = not significant; SCS = Schizophrenia Change Scale.

§Difference favours the treatment group.

\section{COMMENTARY}

CBT has been shown to (a) reduce positive symptoms of schizophrenia when delivered by expert cognitive behaviour therapists ${ }^{1}$ and (b) reduce negative symptoms. ${ }^{2}$

The study by Turkington $e t a l$ was designed to test whether stable schizophrenic patients would improve when the CBT was delivered by CPNs after 10 days of intensive training by experts in CBT. The CPNs also used specially developed educational booklets: 5 for patients and 5 for their caregivers. The group of patients whose caregivers received this intervention fared no better than patients in the CBT group whose caregivers did not receive it. Twice as many dropouts $(22.4 \%)$ in the treatment as usual group as in the CBT group (12.5\%) did not influence outcome assessed on an intent to treat basis.

Improvement in overall symptomatology (but not symptoms of schizophrenia), insight, and depression was found at the end of the study in the CBT group. Whether this effect will be maintained after the intervention has stopped will be reported later. These results are encouraging but also slightly disappointing because the core symptoms of schizophrenia, which have been shown to improve when CBT is delivered by experts, ${ }^{3}$ did not improve when CBT was delivered by CPNs. Further studies are needed to identify the best person to deliver CBT, the time needed to deliver it, and the length of residual effects before CBT becomes a common treatment for people with schizophrenia.

R Williams, MD Royal Jubilee Hospital Victoria, British Columbia, Canada

1 Tarrier N, Beckett R, Harwood S, et al. A trial of two cognitive-behavioural methods of treating drug-resistant residual psychotic symptoms in schizophrenic patients: I. Outcome. Br J Psychiatry 1993;162:524-32.

Sensky T, Turkington D, Kingdon D, et al. A randomized controlled trial of cognitive-behavioral therapy for persistent symptoms in schizophrenia resistant to medication. Arch Gen Psychiatry 2000;57:165-72.

Tarrier N, Yusupoff L, Kinney C, et al. Randomised controlled trial of intensive cognitive behaviour therapy for patients with chronic schizophrenia. BMJ 1998;317:303-7. 